\title{
Neurologic Sequela of Hydrogen Sulfide Poisoning
}

\author{
Byungkuk NAM${ }^{1}$, Hyokyung KIM${ }^{1}$, Younghee $\mathrm{CHOI}^{2}$, Hun $\mathrm{LEE}^{2}$, \\ Eun-Seog HONG ${ }^{3}$, Ji-Kang PARK ${ }^{4}$, Ki-Man LEE $^{5}$ and Yangho KIM ${ }^{2 *}$
}

\author{
${ }^{1}$ Department of Neurology, ${ }^{2}$ Department of Occupational and Environmental Medicine, \\ ${ }^{3}$ Department of Emergency Medicine, ${ }^{4}$ Department of Radiology, \\ ${ }^{5}$ Department of Internal Medicine, Ulsan University Hospital, \#290-3 Cheonha-Dong, Dong-Ku, Ulsan, 682- \\ 060, South Korea
}

Received August 5, 2003 and accepted November 6, 2003

\begin{abstract}
A 25-year-old man, a field operator in a petroleum refinery was found unconscious. He was exposed to hydrogen sulfide and presented with Glasgow Coma Score of 5, severe hypoxemia on arterial blood gas analysis, normal chest radiography, and normal blood pressure. On hospital day 7, his mental state became clear, and neurologic examination showed quadriparesis, profound spasticity, increased tendon reflexes, abnormal Babinski response, and bradykinesia. He was also found to have decreased memory, attention deficits and blunted affect, which suggested general cognitive dysfunction, but which improved soon. MRI scan showed abnormal signals in both basal ganglia and motor cortex, compatible with clinical findings of motor dysfunction.
\end{abstract}

Key words: Hydrogen sulfide, Intoxication, Neurologic sequelae, MR, Hypoxia

Hydrogen sulfide $\left(\mathrm{H}_{2} \mathrm{~S}\right)$ is the second leading cause of toxinrelated death (after carbon monoxide) in the workplace ${ }^{1}$. Acute toxicity of $\mathrm{H}_{2} \mathrm{~S}$ involves mainly the central nervous system and lungs. It may cause variable neurologic symptoms such as dizziness, headache, poor coordination and brief loss of consciousness after exposure to high concentrations of $\mathrm{H}_{2} \mathrm{~S}$. If exposure is transient, recovery is usually complete and rapid. However, in some instances, prolonged or severe exposure leads to a fatal outcome or permanent sequelae ${ }^{2-4}$.

There are a few reports of acute $\mathrm{H}_{2} \mathrm{~S}$ exposure with permanent neurologic deficits ${ }^{2,4)}$. A case of acute $\mathrm{H}_{2} \mathrm{~S}$ intoxication with neurologic sequelae is discussed.

A 25-year-old man had been a field operator in lubricating oil processing at a petroleum refinery for 9 months. He had never worked in other workplace, and had no medical history and family history of medical illness. He had been repairing a separator level gauge connected to $\mathrm{H}_{2} \mathrm{~S}$ compressor in semiclosed spaces without wearing a respirator. When he opened the valve to drain its contents, he might have been exposed to gas leaking from the inter-stage separator chamber. He was

*To whom correspondence should be addressed. found unconscious by another worker wearing a respirator who noticed an offensive odor after approximately $10 \mathrm{~min}$ or more. The patient was rescued by safety officials with selfcontained breathing apparatus, who closed the valve. Vapor analysis of the contents in the separator chamber revealed 14 volume $\%$ of $\mathrm{H}_{2} \mathrm{~S}, 40$ volume $\%$ of hydrogen gas, and 46 volume $\%$ of other carbon species. Industrial hygienist's evaluation revealed no risk of any other hazardous chemical. The patient was transferred to our hospital via local medical clinic approximately $1 \mathrm{~h}$ after being rescued. On arriving at the emergency department of our hospital, he presented with Glasgow Coma Score (GCS) of 5, pulse rate (PR) of 76/min, blood pressure (BP) of $150 / 110 \mathrm{mmHg}$, respiratory rate (RR) of $28 / \mathrm{min}$ and dilated pupils with sluggish response. Initial arterial blood gas study showed $\mathrm{pH} 7.37, \mathrm{PaO}_{2} 46.7 \mathrm{mmHg}$, $\mathrm{PaCO}_{2} 38.4 \mathrm{mmHg}, \mathrm{HCO}_{3} 22 \mathrm{mmol} / \mathrm{L}$. Carboxyhemoglobin $(\mathrm{CoHb})$ was $0.1 \%$. Chest radiography revealed no active lung lesions. Electrocardiogram and hemoglobin level were within normal range. He was treated with antidote therapy of 300 $\mathrm{mg}$ of sodium nitrate and $12.5 \mathrm{~g}$ of sodium thiosulfate immediately, and also was treated with hyperbaric oxygen therapy, and then with mechanical ventilation. Approximately 

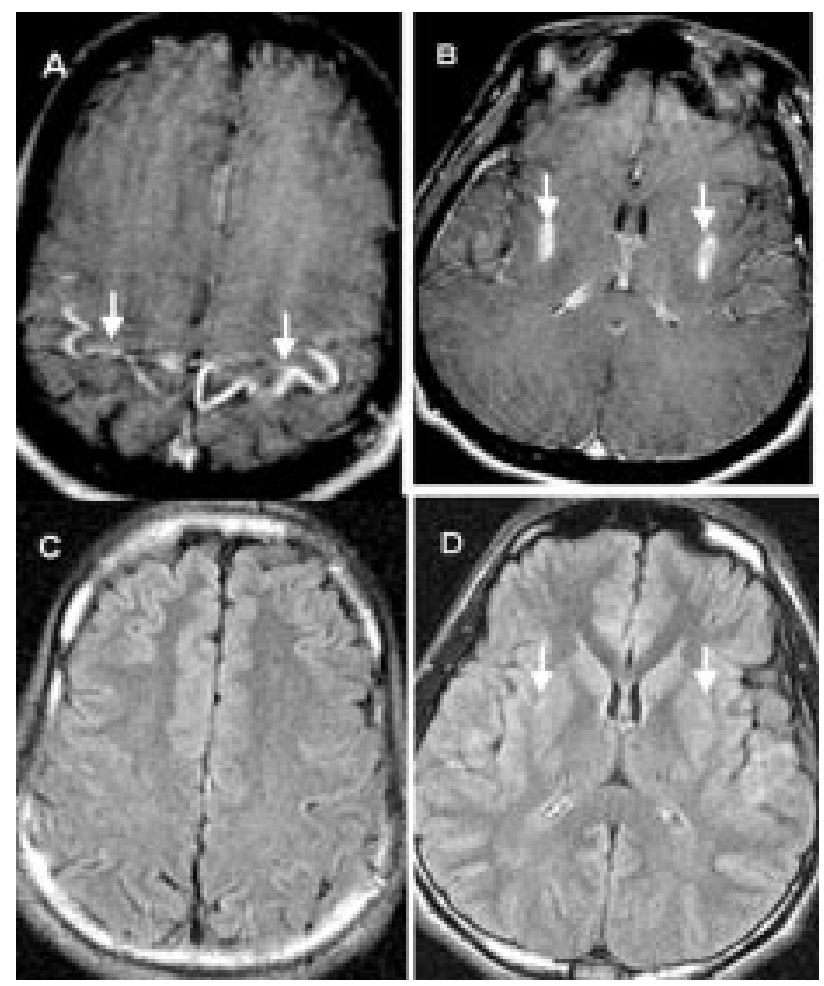

Fig. 1. Initial MR images.

A and B: Fat-suppressed enhanced axial T1-weighted (TR/TE, 525/20 $m s$ ) images at the level of motor cortex and basal ganglia. Thick linear contrast enhancement is seen along the motor cortex, both sides. Strong contrast enhancement is seen in the posterolateral aspect of the putamen, both sides (arrows).

C and D: Axial fluid-attenuated inversion recovery (TR/TE, 10000/160 $m s$ ) image at the level of motor cortex and basal ganglia. No remarkable signal change is seen in the motor cortex, both sides. A mildly increased signal is seen in the outer portion of putamen, both sides (arrows).

$1 \mathrm{~h}$ after initial management, arterial blood gas on $100 \%$ oxygen was improved to $\mathrm{pH}$ of $7.33, \mathrm{PaO}_{2}$ of $246.2 \mathrm{mmHg}, \mathrm{PaCO}_{2}$ of $46.0 \mathrm{mmHg}, \mathrm{HCO}_{3} 24 \mathrm{mmol} / \mathrm{L}$. $\mathrm{CoHb}$ was $0.1 \%$.

Two days after admission, he started to regain consciousness with GCS of 12 and respiration was stabilized on a mechanical ventilator. Ventilatory support was weaned on day 3 . On day 7 , his mental state became clear and he showed correct response to verbal commands. Neurologic examination showed dysarthric speech, quadriparesis with increased muscle tone and Babinski response on both feet. He was also found to have decreased memory, attention deficits and blunted affect, which suggested a general cognitive dysfunction. But this impaired cognitive dysfunction improved after several days. Brain magnetic resonance imaging (MRI) on day 9 , showed contrast enhancement in both basal ganglia and the motor cortex in the T1-weighted image. There was also a finding of mild increased signals in the posterolateral aspect of the

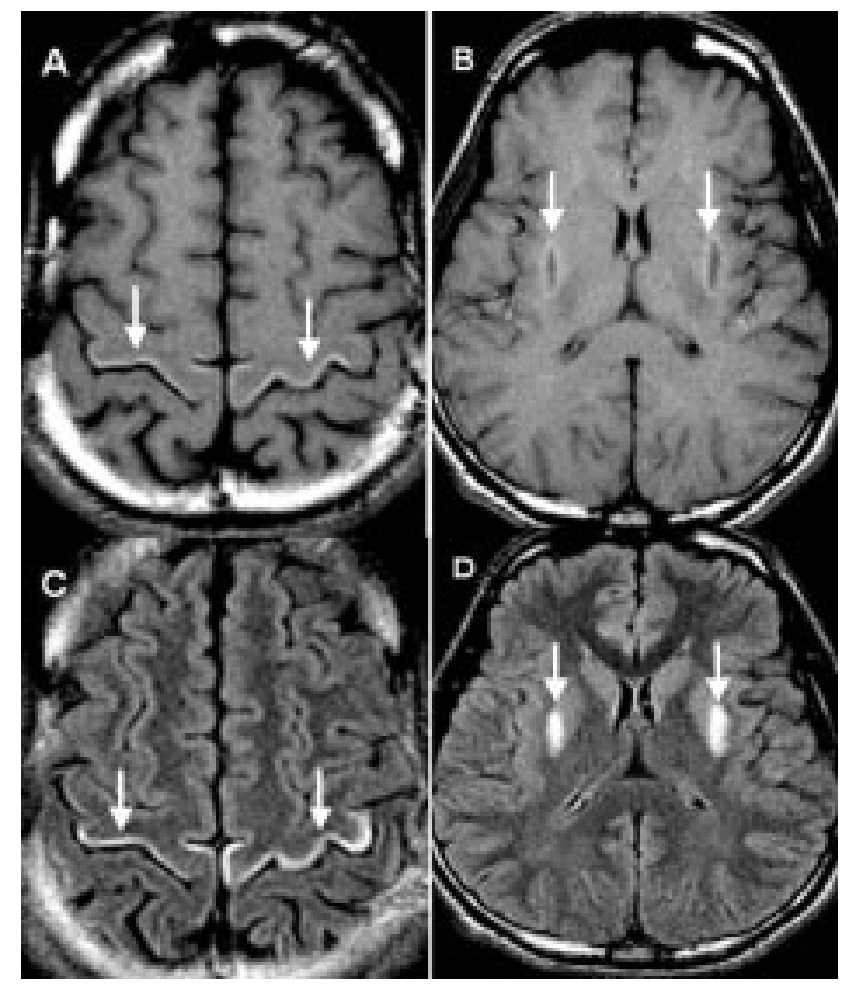

Fig. 2. Follow-up MR images obtained one month after $\mathrm{H}_{2} \mathrm{~S}$ poisoning.

A and B: Non-enhanced axial T1-weighted (TR/TE, 525/20 ms) images at the level of motor cortex and basal ganglia. Increased signal intensity is seen along the motor cortex and the periphery of the lesion is seen in the putamen. The signal change suggests pseudolaminar necrosis in the motor cortex. The central portion of putamen shows low signal, which suggests necrosis (arrows).

$\mathrm{C}$ and D: Axial fluid-attenuated inversion recovery (TR/TE, 10000/160 $m s$ ) image at the level of the motor cortex and basal ganglia. Increased signal intensity is seen in the motor cortex and basal ganglia. The extent of the lesion is similar to that, which was depicted on enhanced T1weighted images (arrows).

putamen on T2 weighted and fluid-attenuated inversion recovery (FLAIR) images (Fig. 1). EEG performed on day 14 showed a normal waking pattern. He then received rehabilitation therapy and was treated with antispastic and dopaminergic drugs to relieve spasticity on whole limbs and mild bradykinesia. About 1 month after exposure, follow-up brain MRI showed signal changes suggesting necrosis on nonenhanced T1-wighted images, and high signal intensities in both basal ganglia and motor cortex on FLAIR images (Fig. 2). At that time his neurologic status had markedly improved compared to initial status. He could walk without assistance but could not run. Activities of daily living were nearly normal despite some clumsiness in activity requiring fine coordination. However, he showed slowed spastic gait, 
Table 1. Findings of neuroimaging after hydrogen sulfide poisoning

\begin{tabular}{|c|c|c|}
\hline Findings & Type of neuroimaging & Authors and date \\
\hline Symmetric low densities of the basal ganglia & $\mathrm{CT}$ & $\begin{array}{l}\text { Gaitonde } \text { et al., } 1987^{24)} \text {; } \\
\text { Matsuo and Cummins, } 1979^{25)}\end{array}$ \\
\hline Cortical atrophy and a localized widening of the 3 rd ventricle & $\mathrm{CT}$ & Tvedt et al., 199120) \\
\hline Slight cortical atrophy & MRI & Tvedt et al., $1991 \mathrm{a} ; \mathrm{b}^{17,20)}$ \\
\hline No lesions & $\begin{array}{l}\text { CT } \\
\text { MRI }\end{array}$ & $\begin{array}{l}\text { Gabbay et al., 200126) } \\
\text { Schneider et al., 1998 }\end{array}$ \\
\hline $\begin{array}{l}\text { Decreased metabolism in thalamus, basal ganglia, temporal and inferior parietal lobe } \\
\text { Decreased metabolism in putamen, amygdala/hippocampal region }\end{array}$ & $\begin{array}{l}\text { PET } \\
\text { SPECT }\end{array}$ & Schneider et al., $1998^{14)}$ \\
\hline Abnormal signals in basal ganglia and motor cortex & MRI & The present study \\
\hline
\end{tabular}

spasticity on whole limbs, impaired fine coordinated movement and mild bradykinesia on detailed neurologic examination. Bedside Mini-mental status examination did not reveal any cognitive dysfunction. Detailed neuropsychological test was performed at 1.5 months after the intoxication. General intelligence, memory, attention, motor function and emotion were tested with the Korean version of the Wechsler Adult Intelligence Scale (K-WAIS), House-Tree-Person Technique (HTP), Wechsler Memory Scale Revised (WMS-R), Wisconsin Card Sorting Test (WCST), color trail test and others. General intelligence was mildly decreased but was concordant with predicted level. It was prominent in performance intelligence as compared to verbal intelligence. Verbal and visual memory function was intact with good retention and recall. But attention was diminished especially in perseverative response. In executive function testing, he performed well except some difficulty in the test requiring sustained attention, which was concordant with marked perseverative errors. His emotional status was not blunted but showed an anxious and depressive tendency.

His neurologic status showed no definite change until 5 months after admission with rehabilitation therapy. Escalation of antispastic and dopaminergic drugs failed to show any effect.

$\mathrm{H}_{2} \mathrm{~S}$ is a mitochondrial toxin that inhibits cytochrome oxidase (cytochrome $\mathrm{aa}_{3}$ ), a terminal enzyme of the respiratory electron transport chain, more potently than cyanide and leads to histotoxic hypoxia. It also has direct cytotoxicity by disrupting disulfide bonds in macromolecules ${ }^{5,6)}$. A phenomenon referred to as "knockdown" has been reported in oil field workers and others to describe sudden, brief loss of consciousness associated with amnesia followed by immediate full recovery after short-term exposure to very high concentrations of
$\mathrm{H}_{2} \mathrm{~S}^{4,7}$. Knockdown is likely a consequence of a direct toxic effect of $\mathrm{H}_{2} \mathrm{~S}$ on the brain ${ }^{8}$. Most victims of acute $\mathrm{H}_{2} \mathrm{~S}$ poisoning who recover do so promptly and completely ${ }^{2,9,10)}$. In a relatively few cases, acute, nonfatal $\mathrm{H}_{2} \mathrm{~S}$ intoxication is followed by permanent neurological sequelae. The preponderance of scientific evidence suggests that this sequence of events is a result of hypoxia secondary to respiratory insufficiency, rather than a direct toxic effect on the brain ${ }^{2,6,11,12)}$. Respiratory insufficiency following exposure to this gas can occur as a consequence of apnea resulting from $\mathrm{H}_{2} \mathrm{~S}$-induced paralysis of the respiratory center of the brain, or can be the result of less specific forms of interference with air flow or oxygen exchange such as airway obstruction or pulmonary edema. Neurological sequelae were divergent and include spasticity, ataxia, tremor, prolonged coma, convulsion, persistent vegetative state and pseudobulbar palsy in other reports ${ }^{13-15}$. Cognitive or behavioral abnormalities such as memory impairment (permanent retrograde amnesia), executive function deficits, slowing in central information processing, and planning deficits were also documented ${ }^{14-17)}$. Cognitive or behavioral deficits are seldom detected in routine screening neurologic examination and seem to be more common than motor deficits, which are easily detectable. Thus some papers suggested that the scanty reports of permanent sequelae are due to lack of detailed neuropsychologic testing and longterm follow-up ${ }^{15}$.

Despite some reports of neurological sequelae caused by acute $\mathrm{H}_{2} \mathrm{~S}$ poisoning, there have been few reports with detailed neuroimaging (Table 1). The MRI findings in the present study suggesting hypoxic brain damage are similar to those in functional neuroimaging studies, and were also compatible with pathologic findings after fatal $\mathrm{H}_{2} \mathrm{~S}$ poisoning that showed greenish discoloration of cerebral cortices and basal ganglia ${ }^{18)}$. Profound structural changes on 
neuroradiologic images in our case suggest that the exposure might have been greater or more prolonged than usual.

Our patient showed various motor symptoms such as quadriparesis, profound spasticity, increased tendon reflexes, abnormal Babinski response, and bradykinesia which suggest that the motor dysfunction resulted from lesions in the motor cortex and basal ganglia although extrapyramidal signs could have been masked by profound pyramidal signs. These clinical findings are compatible with neuroimaging findings in both frontal motor cortices and basal ganglia. These finding were somewhat different from those of other cases with prominent basal ganglial motor dysfunction ${ }^{19,20)}$. Dopamine levels may decline with aging although not typically to levels that compromise functioning. This patient's dopamine system was already damaged as shown in the clinical and radiological findings, thus his risk of subsequently developing Parkinson's disease may be elevated with aging ${ }^{14)}$.

Our case showed relatively minor defects in general cognitive functions including memory, planning, thought processing on detailed neuropsychologic testing except attention deficit. These findings suggest that neuronal damages were confined to the motor cortex and basal ganglia rather than diffuse. A lack of functional imaging study, which could have clarified these points, limits further inference in the present case. Serial neurological testing with functional imaging studies will be necessary in later follow-up.

Pathologically, anoxic injuries can be classified as; hypoxic hypoxia, from decreased partial pressure of blood oxygen, as in patients with hanging or drowning; histotoxic hypoxia, from tissue inability to utilize oxygen, as in cases of mitochondrial toxins like $\mathrm{H}_{2} \mathrm{~S}$ and cyanide, anemic hypoxia, from decreased hemoglobin content or function, as in cases of severe anemia or carbon monoxide poisoning, and hypoxicischemic encephalopathy (HIE), typically seen after cardiac arrest $^{21,22)}$. Pure hypoxic encephalopathy differs from HIE, since cerebral blood flow is preserved or even increased in the former, allowing an effective supply of nutrients and removal of toxic products such as lactic acid. Our patient likely suffered primarily a hypoxic insult (or possibly a combined form of hypoxic hypoxia and histotoxic hypoxia). The results of initial blood gas analysis suggest that hypoxia might be severe and prolonged, and he showed MRI findings similar to cortical laminar necrosis represented in hypoxic brain damage, whereas HIE is associated with extensive lesions throughout the cerebral cortex ${ }^{23)}$. However, he had not hypotension in our hospital and local medical clinic giving the initial management. Cerebral cortices as well as basal ganglia are also known to be susceptible to hypoxic insult because of high oxygen dependency ${ }^{23)}$. Thus it seems that
$\mathrm{H}_{2} \mathrm{~S}$ poisoning can cause profound basal ganglial and cortical lesions. Cyanide, which has the same histotoxic mechanism as $\mathrm{H}_{2} \mathrm{~S}$, was reported to cause similar MR changes in the basal ganglia and central cortex after intoxication ${ }^{23)}$.

In summary, our case of $\mathrm{H}_{2} \mathrm{~S}$ intoxication showed neurologic sequelae of profound motor dysfunction and mild cognitive dysfunction. MRI scan showed abnormal signals in both basal ganglia and the motor cortex, compatible with clinical findings of motor dysfunction.

\section{References}

1) Greenberg M, Hamilton R (1998) The epidemiology of deaths related to toxic exposures in the US workplace, 1992-1996. J Toxicol Clin Toxicol 5, 430.

2) Milby TH (1962) Hydrogen sulfide intoxication. Review of the literature and report of unusual accident resulting in two cases of nonfatal poisoning. J Occup Med 4, 431-7.

3) EPA (US Environmental Protection Agency) (1993) Health assessment document for hydrogen sulfide. Washington, DC: Office of Research and Development, EPA.

4) Guidotti TL (1994) Occupational exposure to hydrogen sulfide in the sour gas industry: some unresolved issues. Int Arch Environ Health 66, 153-60.

5) Kerns W, Kirk M (1998) Cyanide and hydrogen sulfide. In: Goldfrank I, Flomenbaum N, Lewin N, Weisman R, Howland M, Hoffman R (eds). Toxicologic emergencies, $6^{\text {th }}$ ed. 1576-82, Appleton \& Lange, Standford.

6) Beauchamp RO Jr, Bus JS, Popp JA, Boreiko CJ, Andjelovich DA (1984). A critical review of the literature on hydrogen sulfide toxicity. CRC Crit Rev Toxicol 13, 25-97.

7) Smith RP, Gosselin RE (1979) Hydrogen sulfide poisoning. J Occup Med 21, 93-7.

8) Nicholas $P(1975)$ The effects of sulphide on cytochrome $\mathrm{a}_{3}$, isosteric and allosteric shifts of the reduced alpha peak. Biochim Biophys Acta 396, 24-35.

9) NRC (National Research Council) (1979) Hydrogen sulfide. Baltimore: University Park Press.

10) Aves CM (1929) Hydrogen sulfide poisoning in Texas. Texas J Med 24, 761-6.

11) Haggard HW (1925) The toxicology of hydrogen sulfide. J Ind Hyg 7, 113-21.

12) Reiffenstein RJ, Hulbert WC, Roth SH (1992) Toxicity of hydrogen sulfide. Annu Rev Pharmacol Toxicol 32, 109-34. 
13) Schneider JW, Safir EF, Summerville GP, Middleberg RA (1995) Occupational fatality and persistent neurological sequelae after mass exposure to hydrogen sulfide. Am J Emerg Med 13, 199-203.

14) Schneider JS, Tobe EH, Mozley Jr. PD, Barniskis L, Lidsky TI (1998) Persistent cognitive and motor deficits following acute hydrogen sulphide poisoning. Occup Med 48, 255-60.

15) Kilburn KH (1993) Case report: profound neurobehavioral deficits in an oil field worker overcome by hydrogen sulfide. Am J Med Sci 306, 301-5.

16) Kilburn KH (1997) Exposure to reduced sulfur gases impairs neurobehavioral function. South Med J 90, $997-$ 1006.

17) Tvedt B, Edland A, Skyberg K, Forberg, O (1991a) Delayed neuropsychiatric sequelae after acute hydrogen sulfide poisoning: affection of motor function, memory, vision and hearing. Acta Neurol Scand 84, 348-51.

18) Adelson L, Sunshine I (1966) Fatal hydrogen sulfide intoxication. JAMA 81, 375-80.

19) Caronna JJ (1979) Diagnosis, prognosis, and treatment of hypoxic coma. In: Fahn S, Davis J, Rowland L (eds) Advances in neurology, vol. 26, 1-19, Raven Press,
New York.

20) Tvedt B, Skyberg K, Aaserud O, Hobbesland A, Mathiesen T (1991) Brain damage caused by hydrogen sulfide: A follow-up study of six patients. Am J Ind Med 20, 91-101.

21) Levy DE, Caronna JJ, Singer BH, Lapinski RH, Frydman H, Plum F (1985) Predicting outcome from hypoxic-ischemic coma. JAMA 253, 1420-6.

22) Miyamoto O, Auer RN (2000) Hypoxia, hyperoxia, ischemia, and brain necrosis. Neuology 54, 362-70.

23) Rachinger J, Fellner FA, Stieglbauer K, Trenkler J (2002) MR changes after acute cyanide intoxication. Am J Neuroradiol 23, 1398-401.

24) Gaitonde UB, Sellar FJ, O'Hare AE (1987) Long-term exposure to hydrogen sulfide producing subacute encephalopathy in a child. Br Med J 294, 614.

25) Matsuo F, Cummins JW (1979) Neurologic sequele of massive hydrogen sulfide inhalation. Arch Neurol 36, 451-2.

26) Gabbay DS, De Roos F, Perrone J (2001) Twenty-foot fall averts fatality from massive hydrogen sulfide exposure. J Emerg Med 20, 141-4. 